
Tlf: +45 20659888 tbjarnsholt@sund.ku.dk

\section{* Correspondence:}

Denmark.

\title{
Oxygen Restriction Generates Difficult-To-Culture Pathogens
}

Lasse Kvich ${ }^{2}$, Blaine Fritz ${ }^{2}$, Stephanie Crone ${ }^{2}$, Kasper N. Kragh ${ }^{2}$, Mette Kolpen ${ }^{1}$, Majken Sønderholm ${ }^{2}$, Mikael

Andersson ${ }^{3}$, Anders Koch ${ }^{3,4}$, Peter $\emptyset$. Jensen ${ }^{1,2^{*}}$, Thomas Bjarnsholt ${ }^{1,2^{*}}$

${ }^{1}$ Department of Clinical Microbiology, Copenhagen University Hospital - Rigshospitalet, Copenhagen, Denmark.

${ }^{2}$ Costerton Biofilm Center, Department of Immunology and Microbiology, Faculty of Health and Medical Sciences, University of Copenhagen, Denmark.

${ }^{3}$ Department of Epidemiology Research, Statens Serum Institut, Copenhagen, Denmark.

${ }^{4}$ Department of Infectious Diseases, Copenhagen University Hospital - Rigshospitalet, Copenhagen, Denmark.

4 Professor Thomas Bjarnsholt

Costerton Biofilm Center

Department of Immunology and Microbiology

University of Copenhagen

Blegdamsvej 3b, Room 22.2.22

DK-2200 Copenhagen N

32

\section{Keywords:} 8

Abstract: 233 words

Document: 4604 words
23 Associated Professor Peter Ø. Jensen

24 Costerton Biofilm Center

25 Department of Immunology and Microbiology

26 University of Copenhagen

27 Blegdamsvej 3b, Room 24.1.14

28 DK-2200 Copenhagen N

29 Denmark.

30 Tlf: +4530319073

31 peter.oestrup.jensen@ regionh.dk

ORCID: LK 0000-0003-3226-3633, BF 0000-0002-2085-894X, KK 0000-0002-7662-9118, MK 0000-0001-55750384, MS 0000-0001-9576-5775, AK 0000-0001-9205-1048, PJ 0000-0003-1648-7186, TB 0000-0002-8003-7414

P. aeruginosa biofilm / anoxia / biofilm / reactive oxygen species / difficult-to-culture / viable but non-culturable 


\section{Oxygen restriction generates DTC pathogens}

\section{Abstract}

42 Induction of a non-culturable state has been demonstrated for many bacteria. In a clinical

43 perspective, the lack of growth due to these non-culturable bacteria can have major consequences for the diagnosis and treatment of patients. Here we show how anoxic conditioning (restriction of molecular oxygen, $\mathrm{O}_{2}$ ) generates difficult-to-culture (DTC) bacteria during biofilm growth. A significant subpopulation of Pseudomonas aeruginosa entered a DTC state after anoxic conditioning, ranging from five to $90 \%$ of the total culturable population, in both planktonic and biofilm models. Anoxic conditioning also generated DTC subpopulations of Staphylococcus aureus and Staphylococcus epidermidis (89 and $42 \%$ of the total culturable population, respectively).

Growth of the DTC populations were achieved by substituting $\mathrm{O}_{2}$ with $10 \mathrm{mM} \mathrm{NO}_{3}{ }^{-}$as an alternative electron acceptor for anaerobic respiration or, in the case of $P$. aeruginosa, by adding sodium pyruvate or catalase as scavengers against reactive oxygen species (ROS) during aerobic respiration. An increase in normoxic plating due to addition of catalase suggests the molecule hydrogen peroxide as a possible mechanism for induction of DTC $P$. aeruginosa. Anoxic conditioning also generated a true viable but non-culturable (VBNC) population of $P$. aeruginosa that was not resurrected by substituting $\mathrm{O}_{2}$ with $\mathrm{NO}_{3}{ }^{-}$during anaerobic respiration.

These results demonstrate that habituation to an anoxic micro-environment could complicate diagnostic culturing of bacteria, especially in the case of chronic infections where oxygen is restricted due to the host immune response. 
bioRxiv preprint doi: https://doi.org/10.1101/339747; this version posted May 10, 2019. The copyright holder for this preprint (which was not certified by peer review) is the author/funder. All rights reserved. No reuse allowed without permission.

\section{Oxygen restriction generates DTC pathogens}

\section{Importance}

61 Diagnostics of bacteria from chronic infections by standard culture-based methods is challenging.

62 Bacteria in a non-culturable state may contribute to the lack of culturing from these infections.

63 Many stressors are known to induce a non-culturable state, among others the absence of molecular 64 oxygen, which is evident in chronic infections due to high rates of oxygen consumption by the host

65 response. In this study, we have shown that Pseudomonas aeruginosa, Staphylococcus aureus and Staphylococcus epidermidis can enter a non-culturable state after oxygen restriction. Regrowth was not possible using conventional normoxic plating where oxygen served as electron acceptor. Instead, regrowth was enabled during anoxic conditions with added nitrate as alternative electron acceptor. In the case of $P$. aeruginosa we were able to counteract this non-culturable state by adding scavengers for reactive oxygen species during normoxic incubation. This suggest a link between reactive oxygen species and a non-culturable state and it also renders a solution to circumvent this problem in a clinical diagnostic setting. Our findings show that bacteria can habituate to their environment and that it has to be taken into consideration especially when culturing clinical samples e.g. from chronic infections. 


\section{Oxygen restriction generates DTC pathogens}

\section{Introduction}

Clinical laboratories often culture bacteria with enriched media, developed to support maximal growth of particular pathogens. However, even these bacterial human pathogens can enter a growthrestricted, transient state resulting in loss of culturability, especially following antibiotic treatment (Pasquaroli et al., 2013). Non-culturable bacteria are apparent by microscopic identification in clinical cases presenting sign of infection, but no positive cultures. These cases are especially prevalent during chronic infection, where lack of culturability prevents proper diagnosis and treatment (Høiby et al., 2010;Costerton et al., 2011;Høiby et al., 2015).

Two well defined, yet difficult to distinguish, non-culturable states have been described for bacteria: viable but non-culturable (VBNC) and persisters (Oliver, 2010;Wood et al., 2013;Fisher et al., 2017;Kim et al., 2018). Several environmental stresses have been associated with nonculturable states, e.g. oxidative stress, change in temperature or $\mathrm{pH}$, nutrient starvation, change in osmotic concentrations and presence of heavy metals or antibiotics (Oliver, 2010;Ayrapetyan et al., 2015). Oxygen starvation, referred to as anoxic conditioning in this paper, has also shown to induce a non-culturable state in batch cultures of Pseudomonas aeruginosa, but supplementation with nitrate $\left(\mathrm{NO}_{3}{ }^{-}\right)$as an alternative electron acceptor during anoxic plating restored culturability (Binnerup, 1993). The lack of growth during normoxic plating suggests that anoxic conditioning sensitizes a subpopulation of $P$. aeruginosa to $\mathrm{O}_{2}$ or its toxic derivatives, such as reactive oxygen species (ROS). ROS are continuously created during aerobic respiration by incomplete reduction of $\mathrm{O}_{2}$, which is toxic to cells if not scavenged (Fenchel and Finlay, 2008). Presence of ROS has, in some studies, been shown to generate VBNC bacteria (Oliver, 2010;Noor, 2015), but most research has focused on Escherichia coli strains or Vibrio spp., while the effects of ROS on P. aeruginosa and other facultative pathogens are not well characterized. 


\section{Oxygen restriction generates DTC pathogens}

98 Evidence of anoxic zones and anaerobic bacterial activity in chronic infections suggests that

99 100 101 colonizing bacteria, such as $P$. aeruginosa, experience anoxic conditioning (Hassett et al., 2002; Worlitzsch et al., 2002; Kolpen et al., 2014). High rates of $\mathrm{O}_{2}$ consumption by polymorphonuclear leukocytes generate local, anoxic zones and likely play a major role in $\mathrm{O}_{2}$ depletion during chronic infection (Høiby et al., 2015). In addition, other cells of the host may also consume $\mathrm{O}_{2}$, increasing the likelihood of bacteria experiencing anoxia (Worlitzsch et al., 2002).

Many chronic infections are thought to contain bacteria in the biofilm mode of growth (Costerton et al., 2003) and endogenous $\mathrm{O}_{2}$ depletion inside the biofilm (Sønderholm et al., 2018), along with intense $\mathrm{O}_{2}$ consumption by the host immune response (Worlitzsch et al., 2002;Kolpen et al., 2010; Trunk et al., 2010;Kragh et al., 2014;James et al., 2016;Jensen et al., 2017), may therefore increase the number of VBNC bacteria.

This study aimed to determine whether anoxic conditioning generates VBNC cells of $P$. aeruginosa during biofilm growth. Furthermore, we investigated whether ROS are involved in the loss of culturability. 


\section{Oxygen restriction generates DTC pathogens}

\section{Materials and Method}

\section{Bacterial strains}

Pseudomonas aeruginosa (PAO1, ATCC 15692), a catalase A deficient Pseudomonas aeruginosa strain (4katA PAO1) (Hassett et al., 1999), Staphylococcus epidermidis ATCC 14990, Staphylococcus aureus NCTC 8325-4 (methicillin susceptible) (Frees et al., 2004), Staphylococcus aureus USA300 JE2 (MRSA) (Fey et al., 2013), Escherichia coli CFT073 (Welch et al., 2002) and a clinical strain of Enterococcus faecalis from the Department of Clinical Microbiology, Copenhagen University Hospital - Rigshospitalet, Denmark were used in this study.

\section{Agar plates and media}

Primarily lysogeny broth (LB) agar plates were applied in this study. Lysogeny broth (pH 7.5) consisted of $5 \mathrm{~g} / \mathrm{L}$ yeast extract (Oxoid, Roskilde, Denmark), $10 \mathrm{~g} / \mathrm{L}$ tryptone (Oxoid), $10 \mathrm{~g} / \mathrm{L} \mathrm{NaCl}$ (Merck, USA). All plates contained $2 \%$ agarose. Plates used for anoxic growth were supplemented with $10 \mathrm{mM} \mathrm{KNO}_{3}$ (Sigma-Aldrich, USA) to serve as alternative electron acceptor during anoxic plating, referred to as $\mathrm{NO}_{3}{ }^{-}$throughout the paper. All agar plates and media in this study were supplied by the Panum Institute Substrate Department (Copenhagen, DK).

\section{Anoxic growth}

Experiments investigating growth under anoxic conditions were performed in an anaerobic chamber (Concept 400 Anaerobic Workstation, Ruskinn Technology Ltd, UK). The gas atmosphere consisted of $\mathrm{N}_{2} / \mathrm{H}_{2} / \mathrm{CO}_{2}$ (ratio - 80:10:10). Anoxic chamber environment was confirmed with an oxygen sensor (HQ40d multi, HACH Company, USA). All media and chemical solutions used in anaerobic experiments were equilibrated in the anaerobic chamber 3 days prior to experiment. In the case of solutions requiring refrigeration, a minimal volume was applied $(<1 \mathrm{~mL})$, sealed with Parafilm M, and thoroughly shaken upon entry into anaerobic chamber for quick gas equilibration. 


\section{Oxygen restriction generates DTC pathogens}

\section{Direct viable count with LIVE/DEAD staining}

LIVE/DEAD staining was applied to estimate the proportion of viable and non-viable cells in 24hour-old batch cultures and in 16-day-old anoxically conditioned batch cultures of P. aeruginosa. The dyes consisted of two fluorescent nucleic acid stains, the green fluorescent stain (live cells) SYTO9 (Invitrogen, USA) and the red fluorescent stain (dead cells) propidium iodide (PI, SigmaAldrich, USA). SYTO9 penetrates both intact and damaged membranes while PI only stains damaged cells, thereby creating an opportunity to discriminate between live and dead cells (Li et al., 2014). Bacterial suspensions were vortexed thoroughly $(1 \mathrm{~min})$ and sonicated ( 5 min degas +5 minutes sonication) before staining. To stain the cells, one $\mu \mathrm{L}$ of PI and SYTO9 was added to $1 \mathrm{~mL}$ of bacterial suspension and incubated for 15 minutes at room temperature. Suspensions of each biological replicate were then filtered through a $0.2 \mu \mathrm{m}$ black Whatman, Nuclepore Trach-Etch Membrane (Sigma-Aldrich, Denmark) and visualized with confocal laser scanning microscopy using a Zeiss LSM 710 with a 63×/1.4 (numerical aperture) objective (Zeiss, Germany). Fifteen random fields $(135 \mu \mathrm{m} \times 135 \mu \mathrm{m})$ were examined for each filter $(\mathrm{n}=3)$. Enumeration of live (green) and dead (red) bacteria were done with the IMARIS software package (Bitplane AG, Schwitzerland). Briefly, individual particles in each field were identified and counted as bacteria. Particles that were stained with both PI and SYTO9 were considered non-viable and thus counted as dead cells. Conversion of enumerated viable and dead cells to bacterial counts per milliliter was performed as described (Boulos et al., 1999) to compare them with CFU/mL. Briefly, the numbers of particles per $\mathrm{mL}$ were estimated using the following equation $\frac{\text { particles }}{m L}=A *\left(\frac{B}{C}\right) / D$. Where $\mathrm{A}$ is the amount of particles per field, B is the surface of filtration $(\mathrm{mm}), \mathrm{C}$ is the area of the microscopic field and D the volume of the sample filtered. Normoxic and anoxic CFU/mL was carried out simultaneously to estimate the proportion of VBNC cells. CFU/mL was determined in the same way as described for liquid batch cultures. 


\section{Oxygen restriction generates DTC pathogens}

\section{Bead-embedded inoculum of $P$. aeruginosa}

Preparation of alginate beads with $P$. aeruginosa was carried out according to a method described by Sønderholm et al. (Sønderholm et al., 2017). Subsequently, beads were divided (10 beads per vial) into vials (Oximate Vial, PerkinElmer Inc., USA) containing 15 mL LB medium. Vials were sealed with Parafilm M (oxygen permeable) and incubated at $37^{\circ} \mathrm{C}$ on an orbital shaker at $180 \mathrm{rpm}$. Anoxic and normoxic CFU counts were determined from beads and from the surrounding suspension from the same vials on each sampling day (day 3, 6, 8, 12, 19 and 21). Two beads were sampled per biological replicate $(n=4)$. Before determination of $C F U$, the beads were washed twice with $0.9 \% \mathrm{NaCl}$ to remove non-attached cells and transferred to $1.5 \mathrm{~mL}$ microcentrifuge tubes (Sigma-Aldrich, USA). One-hundred microliters of $0.1 \mathrm{M}$ sodium carbonate $\left(\mathrm{Na}_{2} \mathrm{CO}_{3}\right)$ followed by $100 \mu \mathrm{L}$ of $0.04 \mathrm{M}$ citric acid was added to the tubes to dissolve the beads. The suspensions were then sonicated (5 min degas +5 minutes sonication; Bransonic ultrasonic cleaner 2510, Emerson Electric, USA) before ten-fold dilution series were performed in $0.9 \% \mathrm{NaCl}$. CFU was determined by plating three, $10 \mu \mathrm{L}$-drops per dilution per replicate. Anoxic CFU determinations were performed inside an anaerobic chamber on LB plates supplemented with $10 \mathrm{mM} \mathrm{NO}_{3}^{-}$. The same dilution series were applied to normoxic CFU determination outside the anaerobic chamber on LB plates with $10 \mathrm{mM} \mathrm{NO}_{3}{ }^{-}$. Plates were incubated 2 days before counting $\mathrm{CFU}$.

\section{Filter biofilms with $P$. aeruginosa}

This protocol was adapted to grow reproducible biofilms under anoxic and normoxic conditions.

The method has previously been described by Bjarnsholt et al. (2015). The filter biofilms were kept on the same LB plates throughout the experiment. $P$. aeruginosa was propagated from frozen stock and grown overnight in $20 \mathrm{~mL} \mathrm{LB}$ medium at $37^{\circ} \mathrm{C}$ on an orbital shaker at180 rpm. Cultures were adjusted to an optical density of 0.05 (OD 600 ; UV spectrophotometer UV-1800 UV-VIS, Shimadzu corporation, JP) and $10 \mu \mathrm{L}$ was transferred to the cellulose nitrate membrane filters ( $25 \mathrm{~mm}$ in 


\section{Oxygen restriction generates DTC pathogens}

diameter, GE Healthcare Life Sciences, UK). Plates were incubated under normoxic and anoxic conditions and kept in plastic bags with wet paper to avoid dehydration. Two filters were sampled per biological replicate $(n=4)$ on each sampling day (day 1, 3, 7, 15 and 17). Filters were removed, placed in $10 \mathrm{~mL}$ tubes containing $5 \mathrm{~mL} 0.9 \% \mathrm{NaCl}$, vortexed thoroughly (one min.) and sonicated (5 min degas +5 minutes sonication). CFU/mL was determined as previously described.

\section{Liquid batch cultures of $P$. aeruginosa}

P. aeruginosa was propagated from frozen stock and grown overnight in $20 \mathrm{~mL} \mathrm{LB}$ media at $37^{\circ} \mathrm{C}$ and orbitally shaken at $180 \mathrm{rpm}$. Cultures were adjusted to an optical density ( $\left.\mathrm{OD}_{600}\right)$ of 0.1 in glass vials (Oximate Vial) with a final volume of $20 \mathrm{~mL}$ LB. Vials were left to incubate at $37^{\circ} \mathrm{C}$ and orbitally shaken at $180 \mathrm{rpm}$. To create a normoxic environment, half of the vials were incubated with Parafilm M on top (normoxic conditioning), while the rest were incubated with a lid on top creating an anoxic environment (anoxic conditioning). Anoxic and normoxic plating was carried out from normoxic and anoxic conditioned liquid batch cultures (referred to as batch cultures throughout the paper) on each sampling day (day 1, 3, 5, 9, 11, 14, 16, 18, 21 and 28). Normoxic plating was carried out on $\mathrm{LB}$ plates with and without $10 \mathrm{mM} \mathrm{NO}_{3}{ }^{-}$to test whether presence of $\mathrm{NO}_{3}{ }^{-}$ affected the number of CFU. Two $\mathrm{mL}(2 \times 1 \mathrm{~mL}=2$ technical replicates $)$ were sampled per biological replicate $(\mathrm{n}=4)$ on each sampling day. $\mathrm{CFU} / \mathrm{mL}$ was determined as previously described.

\section{Colonies of $P$. aeruginosa}

P. aeruginosa was propagated from frozen stock and grown overnight in $20 \mathrm{~mL} \mathrm{LB}$ media at $37^{\circ} \mathrm{C}$ on an orbital shaker at $180 \mathrm{rpm}$. The cultures were then streaked onto LB plates supplemented with $10 \mathrm{mM} \mathrm{NO}_{3}{ }^{-}$. Plates were incubated under normoxic and anoxic conditions and kept in plastic bags with wet paper to avoid dehydration. A one- $\mu$ l loop was used to sample colony material from each biological replicate $(n=3)$ on each sampling day (day 6, 9, 13, 15 and 20). Colonies were transferred to $1.5 \mathrm{~mL}$ microcentrifuge tubes (Sigma-Aldrich, Denmark) with $0.5 \mathrm{~mL} 0.9 \% \mathrm{NaCl}$, vortexed 


\section{Oxygen restriction generates DTC pathogens}

thoroughly ( $1 \mathrm{~min}$ ) and sonicated (5 min degas +5 minutes sonication). CFU/mL was determined as previously described.

\section{Reactive oxygen species (ROS)}

To elucidate whether growth of anoxically conditioned bacteria was restricted by creation of ROS during aerobic respiration, sodium pyruvate and catalase (Sigma-Aldrich, USA) was tested as ROS scavenger in $\mathrm{LB}$ plates with $10 \mathrm{mM} \mathrm{NO}_{3}{ }^{-}$. Sodium pyruvate $(0.3 \%)$ was tested during anoxic and normoxic plating for 24-hour-old batch cultures and anoxically conditioned 16-day-old batch cultures of $P$. aeruginosa. Catalase ( 50,000 units of catalase per L medium) was tested during anoxic and normoxic plating for anoxically conditioned 16-day-old batch cultures of P. aeruginosa. Furthermore, CFU/mL was also determined from 16-day-old anoxically conditioned batch cultures of $P$. aeruginosa and a catalase A deficient $P$. aeruginosa ( $\triangle$ katA PAO1) to test the influence of ROS. Lastly, creation of ROS was measured along with optical density (OD) at day 1, 8 and 16 for normoxically and anoxically conditioned batch cultures of $P$. aeruginosa. Creation of ROS was measured by adding $5 \mu \mathrm{M}$ 2',7'dichlorodihydrofluorescein diacetate (DCHF-DA; Sigma) to the bacterial suspension. This concentration has previously been used to detect ROS for $P$. aeruginosa (Jensen et al., 2014). Two hundred microliter of anoxically conditioned cultures (OD 600 adjusted to 0.1 in fresh LB medium) was added to each well of black 96-well microtiter plates with transparent flat bottom (16503, Thermo Fisher Scientific, Rochester, NY). OD and ROS was measured over 15 hours at $27^{\circ} \mathrm{C}$ with a VICTOR Multilabel Plate Reader (Perkin Elmer, MA). All experiments consisted of 3-4 biological replicates.

\section{Filter biofilms with other pathogens}

To determine if other bacteria behaved in the same way as $P$. aeruginosa, we investigated the effect of anoxic conditioning on a selected group of pathogens (Staphylococcus epidermidis ATCC 14990, Staphylococcus aureus NCTC 8325-4 (methicillin susceptible), Staphylococcus aureus USA300 


\section{Oxygen restriction generates DTC pathogens}

JE2 (MRSA), Escherichia coli CFT073 and a clinical strain of Enterococcus faecalis). The filter biofilm method was used as described earlier. For the methicillin susceptible strain, CFU was determined in the same way as described for the filters with $P$. aeruginosa. For the remaining strains, CFU was determined at day 1 and 9 on $\mathrm{LB}$ plates supplemented with $10 \mathrm{mM} \mathrm{NO}_{3}{ }^{-} \pm \mathrm{O}_{2}$. Furthermore, CFU was determined on LB plates supplemented with $10 \mathrm{mM} \mathrm{NO}_{3}{ }^{-}$and $0.3 \%$ sodium pyruvate to evaluate the effect of ROS. A minimum of three biological replicates was performed and CFU was carried out in the same way as described earlier.

\section{Statistics}

To evaluate the difference in bacterial growth between incubation conditions (normoxic and anoxic conditioning), a linear regression was used with the difference between the logarithmically transformed values for normoxic and anoxic plating as outcome and with day (categorical) and interaction between day and plating condition (binary) as explanatory variables in SAS Genmod Procedure. The p-value of the interaction term was used as the p-value for the difference in bacterial growth. Log difference was calculated as $\left(\log _{10}[\mathrm{CFU} / \mathrm{mL}]_{\text {anoxic }}-\log _{10}[\mathrm{CFU} / \mathrm{mL}]_{\text {normoxic }}\right)$. The mean and standard error of the mean (SEM) were calculated for recovering bacteria and plotted using GraphPad Prism 6.1 (GraphPad Software, La Jolla, USA). From the ratio between anoxic (CFU $\left.\mathrm{O}_{2}\right)$ and normoxic $\left(\mathrm{CFU}+\mathrm{O}_{2}\right)$ colony counts it was possible to calculate the fraction of DTC bacteria $\left[\%\right.$ DTC bacteria $\left.=\frac{\left(\mathrm{CFU}-\mathrm{O}_{2}\right)-\left(\mathrm{CFU}+\mathrm{O}_{2}\right)}{\left(\mathrm{CFU}-\mathrm{O}_{2}\right)} \times 100\right]$. Data that were not part of the long-term experiments were instead analyzed with a 1-way ANOVA followed by Tukey’s multiple comparison tests or an unpaired t-test. A p-value $\leq 0.05$ was considered statistically significant. The tests were performed with either Prism 6.1 (GraphPad Software, La Jolla, USA) or SAS v.9.4 (SAS Institute Inc., Cary, NC, USA). 


\section{Oxygen restriction generates DTC pathogens}

\section{Results}

Direct viable counts with LIVE/DEAD staining revealed a VBNC $P$. aeruginosa population.

Direct viable counts were carried out for 16-day-old, anoxically conditioned batch cultures of $P$. aeruginosa to investigate if anoxic conditioning could generate a VBNC population. Findings were compared to normoxic and anoxic plating (plating methods) performed on LB plates supplemented with $10 \mathrm{mM} \mathrm{NO}_{3}{ }^{-}$(Fig. 1B). Anoxic plating yielded a significantly $(\mathrm{p}=0.023)$ higher count of colony forming units per milliliter $(\mathrm{CFU} / \mathrm{mL})$ than normoxic plating $(0.85 \log$ values $\pm 0.04 \mathrm{SD})$. When comparing bacterial plate counts with direct viable counting, significantly more viable cells were measured compared to normoxic $(2.31 \log$ values $\pm 0.47 \mathrm{SD}, \mathrm{p}<0.0001)$ and anoxic plating (1.46 log values $\pm 0.5 \mathrm{SD}, \mathrm{p}=0.0009)$. The cells represented by this difference were considered VBNC. Direct viable counts were also performed on 24-hour-old batch cultures to investigate whether findings of VBNC P. aeruginosa were restricted to anoxically conditioned cells. No difference in bacterial counts was observed (Fig. 1A).

\section{Anoxic conditioning generated oxygen intolerant subpopulations of $P$. aeruginosa in biofilm} and planktonic models.

To examine if biofilm growth affected the subsequent normoxic and anoxic plating, $P$. aeruginosa was grown in an alginate-bead biofilm model (Sønderholm et al., 2017). Plate counts were performed on $\mathrm{LB}$ plates supplemented with $10 \mathrm{mM} \mathrm{NO}_{3}{ }^{-}$. Plates were incubated under normoxic and anoxic conditions and plate counts were compared from the beads (biofilm) and the surrounding media (planktonic) of the same vials over a period of 21 days (Fig. 2A and 2B, respectively). The log difference was significantly $(\mathrm{p}=0.003)$ higher for biofilm than planktonic cells (Fig. 2C). The cells represented by this difference were considered to be in a difficult-to- 


\section{Oxygen restriction generates DTC pathogens}

279 culture (DTC) state and ranged from five to $54 \%$ of the entire population from day six to 19 (Fig. 280 S1).

$P$. aeruginosa was also grown anoxically or normoxically on a filter biofilm model using LB plates supplemented with $10 \mathrm{mM} \mathrm{NO}_{3}{ }^{-}$over a period of 17 days. $\mathrm{CFU} / \mathrm{mL}$ was then determined using anoxic and normoxic plating, as above (Fig. 3A and 3B, respectively). The log difference between plating methods was significantly $(\mathrm{p}=0.01)$ higher for anoxically conditioned biofilms than normoxically conditioned biofilms (Fig. 3C). The fraction of DTC $P$. aeruginosa ranged from six to $23 \%$ from day three to 17 (Fig. S1).

Similar results were obtained for anoxically and normoxically conditioned planktonic batch cultures of $P$. aeruginosa over a period of 28 days (Fig. 4A and 4B, respectively). The log difference between plating methods was significantly $(\mathrm{p}<0.0001)$ higher for anoxically conditioned batch cultures (Fig. 3C). The fraction of DTC bacteria ranged from 60 to $90 \%$ from day nine to 21 (Fig. S1).

The effect of anoxic conditioning was further investigated on colonies of P. aeruginosa grown on LB plates supplemented with $10 \mathrm{mM} \mathrm{NO}_{3}{ }^{-}$under anoxic and normoxic conditions over a period of 20 days (Fig. 5A and 5B, respectively). The log difference between plating methods was significantly higher $(\mathrm{p}<0.0001)$ for anoxically conditioned colonies (Fig. 5C). The fraction of DTC P. aeruginosa ranged from 12 to $46 \%$ from day six to 20 (Fig. S1).

\section{$10 \mathrm{mM} \mathrm{NO}{ }^{-}$in $\mathrm{LB}$ plates did not affect $\mathrm{CFU} / \mathrm{mL}$ in batch cultures of $P$. aeruginosa.}

To ensure that presence of $\mathrm{NO}_{3}{ }^{-}$did not affect the number of CFU generated on LB plates, $\mathrm{CFU} / \mathrm{mL}$ was determined anoxically ( $\mathrm{LB}$ plates $+10 \mathrm{mM} \mathrm{NO}_{3}{ }^{-}$) and normoxically (LB plates $\pm 10 \mathrm{mM} \mathrm{NO}_{3}^{-}$) from 24-hour-old batch cultures of $P$. aeruginosa. No difference was observed between type of plating $(\mathrm{p}=0.93)$ : anoxic $\log \mathrm{CFU} / \mathrm{mL}+\mathrm{NO}_{3}{ }^{-}=9.96( \pm 0.22 \mathrm{SD})$, normoxic $\log \mathrm{CFU} / \mathrm{mL}+\mathrm{NO}_{3}{ }^{-}=$ 


\section{Oxygen restriction generates DTC pathogens}

$9.91( \pm 0.10 \mathrm{SD})$ and normoxic $\log \mathrm{CFU} / \mathrm{mL}^{-} \mathrm{NO}_{3}{ }^{-}=9.91( \pm 0.14 \mathrm{SD})$. Furthermore, there was no effect of $\mathrm{NO}_{3}{ }^{-}$supplementation on normoxic plating in the prolonged experiment with 28-day-old batch cultures (Fig. 4A and 4B). It was not possible to detect growth of $P$. aeruginosa on LB plates under anoxic conditions without $\mathrm{NO}_{3}{ }^{-}$, but growth was observed when these plates subsequently were placed under normoxic conditions.

\section{Oxidative stress restricted the growth of anoxically conditioned $P$. aeruginosa when re-grown}

\section{in a normoxic environment.}

Bacteria from 16-day-old anoxically and normoxically conditioned batch cultures of $P$. aeruginosa were plated on $10 \mathrm{mM} \mathrm{NO}_{3}{ }^{-} \mathrm{LB}$ plates \pm sodium pyruvate and \pm catalase to investigate whether formation of ROS contributed to the DTC state induced by anoxic conditioning. Presence of sodium pyruvate as a ROS scavenger (Mizunoe et al., 1999) significantly $(\mathrm{p}=0.04)$ increased normoxic CFU/mL compared to plating without sodium pyruvate (Fig. 6B). This was not the case in 24-hourold batch cultures of $P$. aeruginosa $(\mathrm{p}=0.62)$, indicating that the effect was restricted to anoxically conditioned cells (Fig. 6A). Presence of catalase also significantly $(\mathrm{p}=0.03)$ improved normoxic plate counts compared to normoxic plating without catalase (Fig. 6B). These results show that hydrogen peroxide is involved in the induction of a DTC state created by anoxic conditioning. To add proof to this hypothesis, a similar experiment was carried out with a catalase deficient $P$. aeruginosa mutant ( $\triangle$ katA PAO1), which is more susceptible to oxidative stress (Hassett et al., 1999;Jensen et al., 2014). The log difference between plating methods for the $\Delta k a t A$ mutant and reference strain was significantly $(\mathrm{p}=0.00002$, unpaired t-test $)$ different. These log difference values were $3.02 \pm 0.05 \mathrm{SD}$ and $1.61 \pm 0.07 \mathrm{SD}$ for $\Delta k a t A \mathrm{PAO} 1$ and the reference strain, respectively (Fig. 6C). Moreover, measurement of ROS and optical density (OD) was carried out for $P$. aeruginosa at day 1,8 and 16 from anoxically and normoxically conditioned batch cultures. 


\section{Oxygen restriction generates DTC pathogens}

These results showed creation of ROS during normoxic growth. The longer PAO1 was anoxically conditioned; the lower was the following normoxic growth, as measured by OD. This effect was less pronounced for normoxically-conditioned cells (Fig.7 A-C).

\section{Anoxic conditioning affects Staphylococcus aureus and Staphylococcus epidermidis, but not}

\section{Escherichia coli and Enterococcus faecalis}

The effect of anoxic conditioning was then tested on a selected group of pathogens to determine if this phenomenon was restricted to P. aeruginosa. S. aureus (methicillin susceptible) was tested as described in the $P$. aeruginosa filter biofilm setup. Plate counts for anoxically and normoxically conditioned filters was determined (Fig. 8A and 8B, respectively). The log difference between plating method was significantly higher $(\mathrm{p}<0.001)$ when plate counts were performed from anoxically conditioned filter biofilms than from normoxically conditioned filter biofilms (Fig. 8C). The fraction of DTC S. aureus ranged from three to $89 \%$ from day one to day 17 (Fig. S1). Since both $P$. aeruginosa and $S$. aureus demonstrated effects of anoxic conditioning, a smaller experiment was initiated to test other pathogens. The effect was determined on LB plates supplemented with 10 $\mathrm{mM} \mathrm{NO}_{3}{ }^{-} \pm$sodium pyruvate to investigate if ROS were involved in the lack of growth. Both $S$. aureus (MRSA) and S. epidermidis showed effects of anoxic conditioning, resulting in an significant $(p=0.01$ and $p=0.03$, respectively) increase in $C F U / m L$ during anoxic plating compared to normoxic plating (Fig. S2). The fraction of DTC S. aureus (MRSA) and S. epidermidis was 36 and $42 \%$ at day 9 , respectively. There was no observed effect of sodium pyruvate during normoxic plating for these two strains. In the case of E. coli and E. faecalis, there was no observed effect of anoxic conditioning (Fig. S3). 


\section{Oxygen restriction generates DTC pathogens}

351

\section{Discussion}

\section{DTC and VBNC P. aeruginosa}

In the current study, we demonstrate that plate counting with $P$. aeruginosa is significantly affected by anoxic conditioning when cultured in the presence of atmospheric oxygen levels. A DTC state was created after only a few days of anoxic conditioning in both biofilm and planktonic models. DTC $P$. aeruginosa was observed in the beads from the bead biofilm model, but not in the surrounding suspension, despite that the cultures had full access to atmospheric oxygen. This indicates that oxygen restriction within a biofilm generates a DTC subpopulation. The DTC state, detected as increased growth during anoxic plating with $\mathrm{NO}_{3}^{-}$, has previously been generated in planktonic $P$. aeruginosa by energy starvation after cultivation without $\mathrm{O}_{2}$ as electron acceptor for aerobic respiration (Binnerup, 1993). In vitro biofilms of $P$. aeruginosa may contain internal anoxic zones (Walters et al., 2003;Kolpen et al., 2016), so we hypothesized that anoxia inside the biofilm contributes to the induction of DTC P. aeruginosa. Accordingly, DTC P. aeruginosa was only observed in the filter biofilm model and the colony model when the model was anoxically conditioned. Interestingly, we found that $99.68 \%$ of the population was VBNC with the LIVE/DEAD assay after anoxic conditioning. LIVE/DEAD staining is based upon membrane permeability and is only an approximation of true viability. Cells that were stained both red and green (resulting in yellow) were counted as dead cells but may still be viable.

Approximately $50 \%$ of the population in the alginate beads was DTC even though they were kept in normoxically-conditioned vials. In comparison, the fraction of DTC cells was approximately 90 $\%$ in the anoxically conditioned batch cultures. The difference (90\% vs. $50 \%$ ) may be explained by the fact that a majority of the bacteria in the beads are peripherally located where they have increased access to oxygen compared to the center of the beads (Sønderholm et al., 2017). In comparison, bacteria from the anoxically conditioned batch cultures were fully deprived of $\mathrm{O}_{2}$. In 


\section{Oxygen restriction generates DTC pathogens}

the present study, the effect of anoxic conditioning was restricted to an intermediate period. This is probably due to the static methodological setup. Dynamic processes, such as entry of nutrients and removal of waste, occur during infection and are not modeled here (Brown et al., 2008).

Nevertheless, this is not the first time a "resuscitation window" has been described for nonculturable bacteria. Similar studies have shown that VBNC bacteria can only be detected in an intermediate period of culturing (Pinto et al., 2015).

\section{ROS restricts growth of anoxically conditioned $P$. aeruginosa}

The DTC fraction of bacteria in this study was $\mathrm{O}_{2}$ intolerant given that growth only was achievable when $\mathrm{NO}_{3}{ }^{-}$served as an alternative electron acceptor during anaerobic respiration. This led us to investigate whether this phenomena was due to oxidizing properties of ROS created by incomplete reduction of $\mathrm{O}_{2}$ during aerobic respiration (Fenchel and Finlay, 2008). Sodium pyruvate increased counts for anoxically conditioned $P$. aeruginosa during normoxic plating (roughly $43 \%$ of the DTC population) and we believe that it was due to its properties as a ROS scavenger (Mizunoe et al., 1999). Accordingly, $0.3 \%$ sodium pyruvate has been used to resuscitate non-culturable populations of S. aureus (Pasquaroli et al., 2013). Catalase also increased counts during normoxic plating (roughly $50 \%$ of the DTC population), indicating that hydrogen peroxide is involved in the induction of a DTC state. The effect of ROS was further confirmed by the reduced growth of a catalase A deficient $P$. aeruginosa mutant ( $\triangle$ katA PAO1) after anoxic conditioning. Finally, measurements of ROS along with OD showed that anoxically conditioned batch cultures of $P$. aeruginosa created more ROS when regrown under atmospheric conditions the longer they were deprived from oxygen, resulting in an accumulation of ROS and a reduction in growth represented by lower OD measurements. These results indicate that accumulation of ROS during aerobic respiration has an impact on normoxic plate counting when $P$. aeruginosa has been anoxically conditioned. Furthermore, it seems that hydrogen peroxide is involved in this loss of culturing. It 


\section{Oxygen restriction generates DTC pathogens}

has been suggested that VBNC cells cannot be resuscitated by addition of ROS scavengers and that "revived" cells in the presence of ROS scavengers are only injured cells and not VBNC cells (Pinto et al., 2015). It was not possible to determine whether DTC bacteria in this study were in an injured state.

\section{S. epidermidis and $S$. aureus also become DTC after anoxic conditioning}

Additional experiments were conducted to elucidate whether anoxic conditioning generated DTC sub-populations in other facultative pathogens. Filter biofilms of methicillin susceptible $S$. aureus showed the same effects of anoxic conditioning as $P$. aeruginosa. These experiments were also repeated for S. epidermidis, S. aureus (MRSA), E. coli and E. faecalis. Both S. epidermidis and $S$. aureus were significantly ( $\mathrm{p}=0.01$ and $\mathrm{p}=0.03$, respectively) affected by anoxic conditioning, whereas E. coli and E. faecalis were not. The results in this study points toward an intermediate period where anoxic conditioned bacteria are benefitted by anoxic incubation with nitrate as alternative electron acceptor. We cannot rule out that we missed the period where E. coli and $E$. faecalis were DTC, given that they were tested at selected days. No effect of sodium pyruvate was found during normoxic plating for any of these tested organisms, suggesting that ROS is not involved in the loss of culturability for these pathogens, but additional ROS scavengers should be tested.

\section{Conclusion}

A non-culturable state can be induced by several physiological stresses and our knowledge in this area is expanding, though far from fully resolved. In this study, we demonstrate that anoxic conditioning generates a VBNC subpopulation in $P$. aeruginosa batch-cultures. Furthermore, we demonstrate that anoxic conditioning generates DTC sub-populations of P. aeruginosa, $S$. aureus and S. epidermidis during biofilm growth. The DTC population was only able to grow under anoxic 
bioRxiv preprint doi: https://doi.org/10.1101/339747; this version posted May 10, 2019. The copyright holder for this preprint (which was not certified by peer review) is the author/funder. All rights reserved. No reuse allowed without permission.

\section{Oxygen restriction generates DTC pathogens}

conditions in the presence of $\mathrm{NO}_{3}{ }^{-}$as an alternative electron acceptor. In the case of P. aeruginosa, this phenomenon was explained by creation of lethal amounts of ROS during aerobic respiration and the bacteria's inability to neutralize it.

\section{Data availability}

The data generated in the current study are available from the corresponding author on reasonable request.

\section{Funding information}

This study was supported by grants from The Lundbeck foundation (R105-A9791) to TB and by a Novo-Nordisk Tandem (ref.nr. NNF16OC0023482) grant to MK. The funders had no role in study design, data collection and interpretation, or the decision to submit the work for publication

\section{Author contributions}

LK performed the majority of the experiments. MK, MS, BFG, SC and KNK also performed experiments. TB, PØJ, KNK AK, and LK conceived and designed experiments. LK wrote the manuscript. MA and PØJ performed statistics. All authors analyzed data. All authors contributed to and corrected the manuscript.

\section{Conflict of interest}

The authors declare that they have no conflict of interest. 


\section{Oxygen restriction generates DTC pathogens}

\section{References}

Ayrapetyan, M., Williams, T.C., Baxter, R., and Oliver, J.D. (2015). Viable but Nonculturable and Persister Cells Coexist Stochastically and Are Induced by Human Serum. Infect Immun 83, 4194-4203.

Binnerup, S.J., And J. Sorensen. (1993). Long-term oxidant deficiency in Pseudomonas aeruginosa PAO303 results in cells which are non-culturable under aerobic conditions. FEMS Microbiol. Ecol. 13, 79-84.

Boulos, L., Prevost, M., Barbeau, B., Coallier, J., and Desjardins, R. (1999). LIVE/DEAD BacLight : application of a new rapid staining method for direct enumeration of viable and total bacteria in drinking water. J Microbiol Methods 37, 77-86.

Brown, S.A., Palmer, K.L., and Whiteley, M. (2008). Revisiting the host as a growth medium. Nat Rev Microbiol 6, 657-666.

Costerton, J.W., Post, J.C., Ehrlich, G.D., Hu, F.Z., Kreft, R., Nistico, L., Kathju, S., Stoodley, P., Hall-Stoodley, L., Maale, G., James, G., Sotereanos, N., and Demeo, P. (2011). New methods for the detection of orthopedic and other biofilm infections. FEMS Immunol Med Microbiol 61, 133-140.

Costerton, W., Veeh, R., Shirtliff, M., Pasmore, M., Post, C., and Ehrlich, G. (2003). The application of biofilm science to the study and control of chronic bacterial infections. J Clin Invest 112, 1466-1477.

Fenchel, T., and Finlay, B. (2008). Oxygen and the spatial structure of microbial communities. Biol Rev Camb Philos Soc 83, 553-569.

Fey, P.D., Endres, J.L., Yajjala, V.K., Widhelm, T.J., Boissy, R.J., Bose, J.L., and Bayles, K.W. (2013). A genetic resource for rapid and comprehensive phenotype screening of nonessential Staphylococcus aureus genes. MBio 4, e00537-00512. 


\section{Oxygen restriction generates DTC pathogens}

Fisher, R.A., Gollan, B., and Helaine, S. (2017). Persistent bacterial infections and persister cells. Nat Rev Microbiol 15, 453-464.

Frees, D., Chastanet, A., Qazi, S., Sørensen, K., Hill, P., Msadek, T., and Ingmer, H. (2004). Clp ATPases are required for stress tolerance, intracellular replication and biofilm formation in Staphylococcus aureus. Mol Microbiol 54, 1445-1462.

Hassett, D.J., Cuppoletti, J., Trapnell, B., Lymar, S.V., Rowe, J.J., Yoon, S.S., Hilliard, G.M., Parvatiyar, K., Kamani, M.C., Wozniak, D.J., Hwang, S.H., Mcdermott, T.R., and Ochsner, U.A. (2002). Anaerobic metabolism and quorum sensing by Pseudomonas aeruginosa biofilms in chronically infected cystic fibrosis airways: rethinking antibiotic treatment strategies and drug targets. Adv Drug Deliv Rev 54, 1425-1443.

Hassett, D.J., Ma, J.F., Elkins, J.G., Mcdermott, T.R., Ochsner, U.A., West, S.E., Huang, C.T., Fredericks, J., Burnett, S., Stewart, P.S., Mcfeters, G., Passador, L., and Iglewski, B.H. (1999). Quorum sensing in Pseudomonas aeruginosa controls expression of catalase and superoxide dismutase genes and mediates biofilm susceptibility to hydrogen peroxide. Mol Microbiol 34, 1082-1093.

Høiby, N., Bjarnsholt, T., Givskov, M., Molin, S., and Ciofu, O. (2010). Antibiotic resistance of bacterial biofilms. Int J Antimicrob Agents 35, 322-332.

Høiby, N., Bjarnsholt, T., Moser, C., Bassi, G.L., Coenye, T., Donelli, G., Hall-Stoodley, L., Hola, V., Imbert, C., Kirketerp-Møller, K., Lebeaux, D., Oliver, A., Ullmann, A.J., and Williams, C. (2015). ESCMID guideline for the diagnosis and treatment of biofilm infections 2014. Clin Microbiol Infect 21 Suppl 1, S1-25.

James, G.A., Ge Zhao, A., Usui, M., Underwood, R.A., Nguyen, H., Beyenal, H., Delancey Pulcini, E., Agostinho Hunt, A., Bernstein, H.C., Fleckman, P., Olerud, J., Williamson, K.S., Franklin, M.J., and Stewart, P.S. (2016). Microsensor and transcriptomic signatures of 


\section{Oxygen restriction generates DTC pathogens}

oxygen depletion in biofilms associated with chronic wounds. Wound Repair Regen 24, 373-383.

Jensen, P.Ø., Briales, A., Brochmann, R.P., Wang, H., Kragh, K.N., Kolpen, M., Hempel, C., Bjarnsholt, T., Høiby, N., and Ciofu, O. (2014). Formation of hydroxyl radicals contributes to the bactericidal activity of ciprofloxacin against Pseudomonas aeruginosa biofilms. Pathog Dis 70, 440-443.

Jensen, P.Ø., Kolpen, M., Kragh, K.N., and Kühl, M. (2017). Microenvironmental characteristics and physiology of biofilms in chronic infections of CF patients are strongly affected by the host immune response. Apmis 125, 276-288.

Kim, J.S., Chowdhury, N., Yamasaki, R., and Wood, T.K. (2018). Viable but non-culturable and persistence describe the same bacterial stress state. Environ Microbiol.

Kolpen, M., Hansen, C.R., Bjarnsholt, T., Moser, C., Christensen, L.D., Van Gennip, M., Ciofu, O., Mandsberg, L., Kharazmi, A., Doring, G., Givskov, M., Høiby, N., and Jensen, P.Ø. (2010). Polymorphonuclear leucocytes consume oxygen in sputum from chronic Pseudomonas aeruginosa pneumonia in cystic fibrosis. Thorax $65,57-62$.

Kolpen, M., Kühl, M., Bjarnsholt, T., Moser, C., Hansen, C.R., Liengaard, L., Kharazmi, A., Pressler, T., Høiby, N., and Jensen, P.Ø. (2014). Nitrous oxide production in sputum from cystic fibrosis patients with chronic Pseudomonas aeruginosa lung infection. PLoS One 9, e84353.

Kolpen, M., Mousavi, N., Sams, T., Bjarnsholt, T., Ciofu, O., Moser, C., Kuhl, M., Hoiby, N., and Jensen, P.O. (2016). Reinforcement of the bactericidal effect of ciprofloxacin on Pseudomonas aeruginosa biofilm by hyperbaric oxygen treatment. Int J Antimicrob Agents 47, 163-167. 


\section{Oxygen restriction generates DTC pathogens}

Kragh, K.N., Alhede, M., Jensen, P.Ø., Moser, C., Scheike, T., Jacobsen, C.S., Seier Poulsen, S., Eickhardt-Sørensen, S.R., Trostrup, H., Christoffersen, L., Hougen, H.P., Rickelt, L.F., Kühl, M., Høiby, N., and Bjarnsholt, T. (2014). Polymorphonuclear leukocytes restrict growth of Pseudomonas aeruginosa in the lungs of cystic fibrosis patients. Infect Immun 82, 4477-4486.

Li, L., Mendis, N., Trigui, H., Oliver, J.D., and Faucher, S.P. (2014). The importance of the viable but non-culturable state in human bacterial pathogens. Front Microbiol 5, 258.

Mizunoe, Y., Wai, S.N., Takade, A., and Yoshida, S. (1999). Restoration of culturability of starvation-stressed and low-temperature-stressed Escherichia coli O157 cells by using H2O2-degrading compounds. Arch Microbiol 172, 63-67.

Noor, R. (2015). Mechanism to control the cell lysis and the cell survival strategy in stationary phase under heat stress. Springerplus 4, 599.

Oliver, J.D. (2010). Recent findings on the viable but nonculturable state in pathogenic bacteria. FEMS Microbiol Rev 34, 415-425.

Pasquaroli, S., Zandri, G., Vignaroli, C., Vuotto, C., Donelli, G., and Biavasco, F. (2013). Antibiotic pressure can induce the viable but non-culturable state in Staphylococcus aureus growing in biofilms. J Antimicrob Chemother 68, 1812-1817.

Pinto, D., Santos, M.A., and Chambel, L. (2015). Thirty years of viable but nonculturable state research: unsolved molecular mechanisms. Crit Rev Microbiol 41, 61-76.

Sønderholm, M., Koren, K., Wangpraseurt, D., Jensen, P.Ø., Kolpen, M., Kragh, K.N., Bjarnsholt, T., and Kühl, M. (2018). Tools for studying growth patterns and chemical dynamics of aggregated Pseudomonas aeruginosa exposed to different electron acceptors in an alginate bead model. NPJ Biofilms Microbiomes 4, 3 . 


\section{Oxygen restriction generates DTC pathogens}

Sønderholm, M., Kragh, K.N., Koren, K., Jakobsen, T.H., Darch, S.E., Alhede, M., Jensen, P.Ø., Whiteley, M., Kühl, M., and Bjarnsholt, T. (2017). Pseudomonas aeruginosa Aggregate Formation in an Alginate Bead Model System Exhibits In Vivo-Like Characteristics. Appl Environ Microbiol 83.

Trunk, K., Benkert, B., Quack, N., Munch, R., Scheer, M., Garbe, J., Jansch, L., Trost, M., Wehland, J., Buer, J., Jahn, M., Schobert, M., and Jahn, D. (2010). Anaerobic adaptation in Pseudomonas aeruginosa: definition of the Anr and Dnr regulons. Environ Microbiol 12, 1719-1733.

Walters, M.C., 3rd, Roe, F., Bugnicourt, A., Franklin, M.J., and Stewart, P.S. (2003). Contributions of antibiotic penetration, oxygen limitation, and low metabolic activity to tolerance of Pseudomonas aeruginosa biofilms to ciprofloxacin and tobramycin. Antimicrob Agents Chemother 47, 317-323.

Welch, R.A., Burland, V., Plunkett, G., 3rd, Redford, P., Roesch, P., Rasko, D., Buckles, E.L., Liou, S.R., Boutin, A., Hackett, J., Stroud, D., Mayhew, G.F., Rose, D.J., Zhou, S., Schwartz, D.C., Perna, N.T., Mobley, H.L., Donnenberg, M.S., and Blattner, F.R. (2002). Extensive mosaic structure revealed by the complete genome sequence of uropathogenic Escherichia coli. Proc Natl Acad Sci U S A 99, 17020-17024.

Wood, T.K., Knabel, S.J., and Kwan, B.W. (2013). Bacterial persister cell formation and dormancy. Appl Environ Microbiol 79, 7116-7121.

Worlitzsch, D., Tarran, R., Ulrich, M., Schwab, U., Cekici, A., Meyer, K.C., Birrer, P., Bellon, G., Berger, J., Weiss, T., Botzenhart, K., Yankaskas, J.R., Randell, S., Boucher, R.C., and Doring, G. (2002). Effects of reduced mucus oxygen concentration in airway Pseudomonas 


\section{Oxygen restriction generates DTC pathogens}

563

Figure legends

A

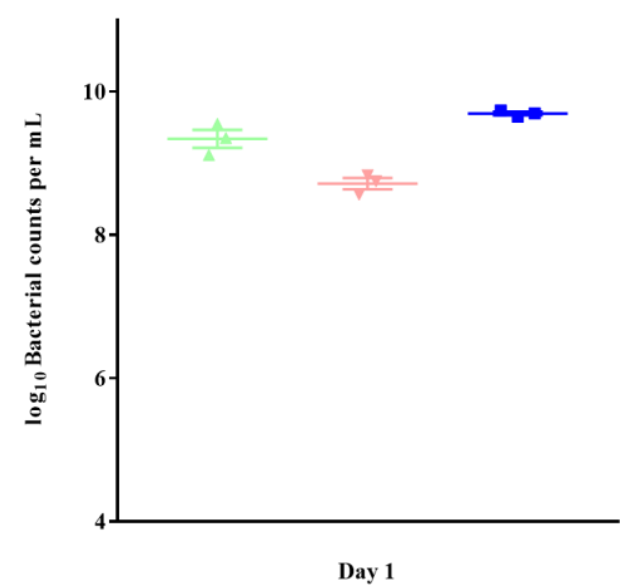

B

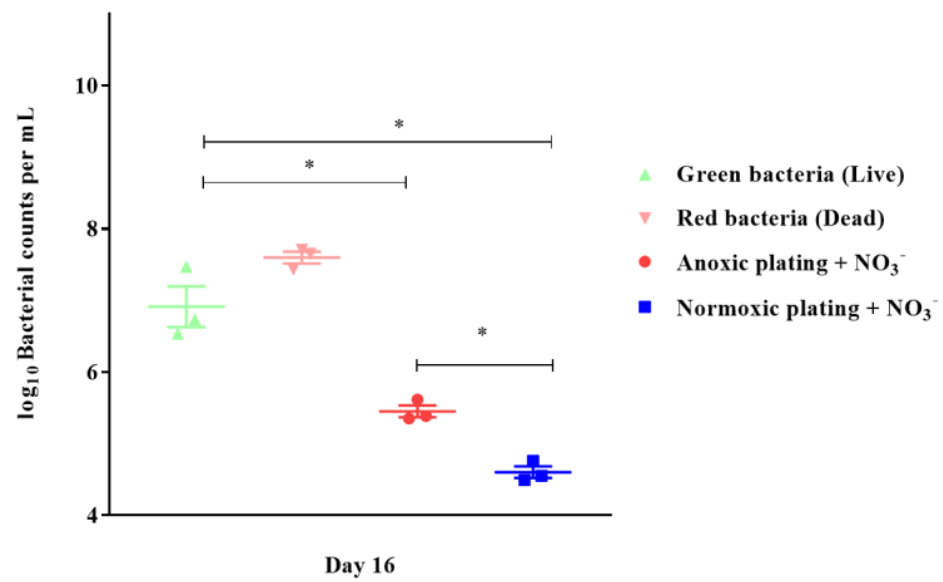

564

565

566

567

Fig. 1 - Direct viable counting reveals a viable but non-culturable population of Pseudomonas aeruginosa (PAO1) after anoxic conditioning

Bacterial counts per milliliter were determined with plate counting and direct viable counting from 24-hour-old batch cultures (A) and from 16-day-old anoxic conditioned batch cultures (B) of PAO1. Bacteria were stained with LIVE/DEAD staining to estimate the proportion of viable ("live") and non-viable ("dead") cells. There was significantly more viable bacterial counts when applying direct viable counting in comparison to normoxic plating ( $\mathrm{p}<0.0001$, one-way ANOVA test) and anoxic plating ( $\mathrm{p}=0.0009$, one-way ANOVA). Anoxic plating yielded significantly higher bacterial counts ( $\mathrm{p}=0.023$, one-way ANOVA test) than normoxic plating. Symbols with error bars indicate the mean $\pm \operatorname{SEM}(n=3) .+\mathrm{NO}_{3}{ }^{-}$refers to the addition of $10 \mathrm{mM} \mathrm{KNO}_{3}$ to $\mathrm{LB}$ agar plates. 


\section{Oxygen restriction generates DTC pathogens}

A

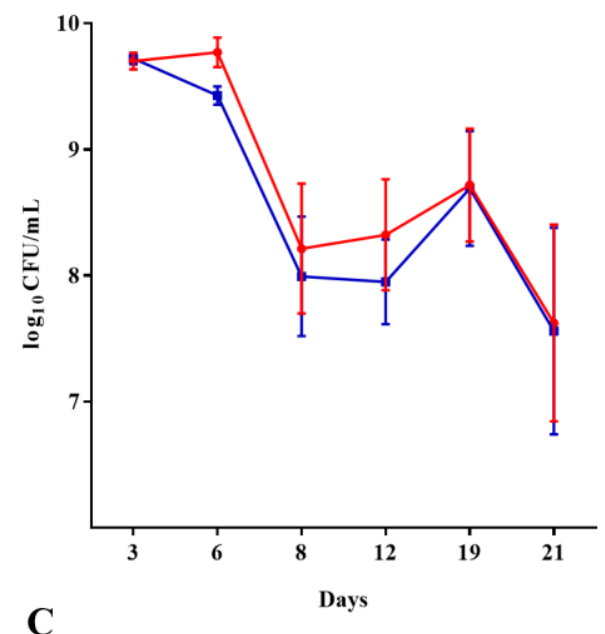

C

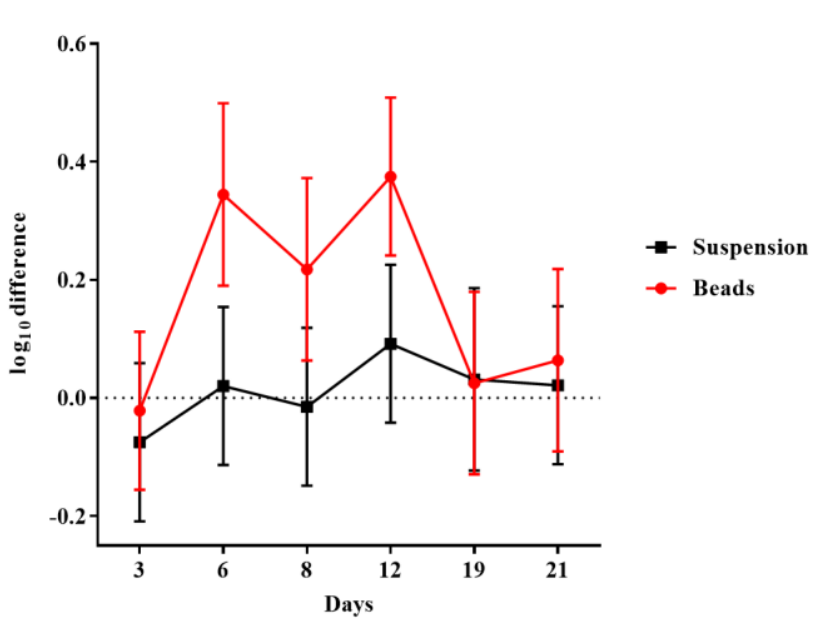

B

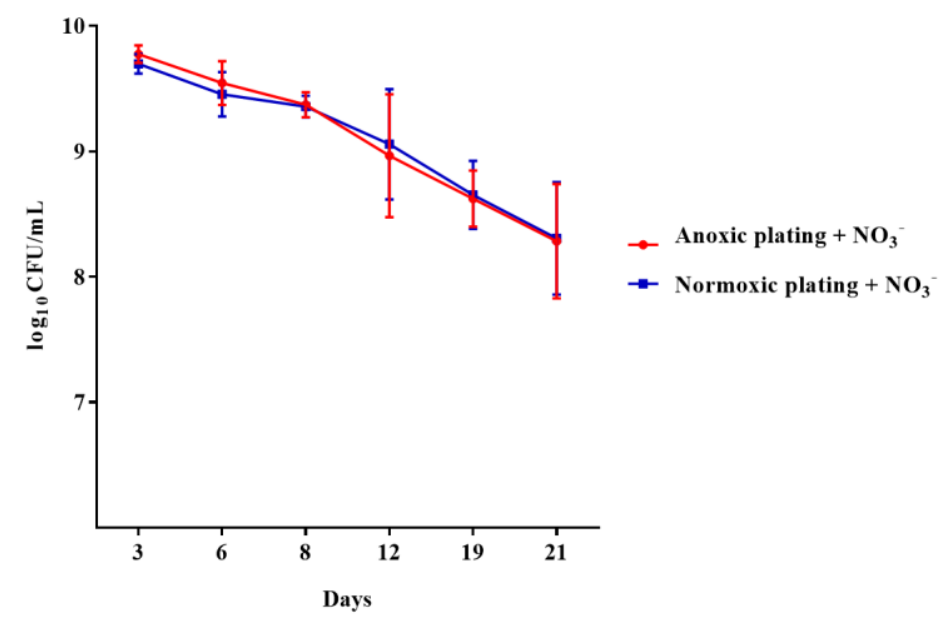

577

\section{Fig. 2 - An oxygen intolerant subpopulation of Pseudomonas aeruginosa (PAO1) was} generated in the bead biofilm model

Normoxic and anoxic colony forming units per milliliter (CFU/mL) of PAO1 over 21 days from the beads (A) and the surrounding suspension (B). Symbols with error bars indicate the mean \pm SEM (n $=4) .+\mathrm{NO}_{3}{ }^{-}$refers to the addition of $10 \mathrm{mM} \mathrm{KNO}_{3}$ to $\mathrm{LB}$ agar plates. The log difference $(\mathrm{C})$ represents the difference in mean $\log \mathrm{CFU} / \mathrm{mL}$ between plating methods from the suspension and the beads, respectively. The log difference was significantly higher ( $p=0.003$, linear regression) in the beads than the surrounding suspension. Symbols with error bars indicate the mean + confidence intervals. 


\section{Oxygen restriction generates DTC pathogens}
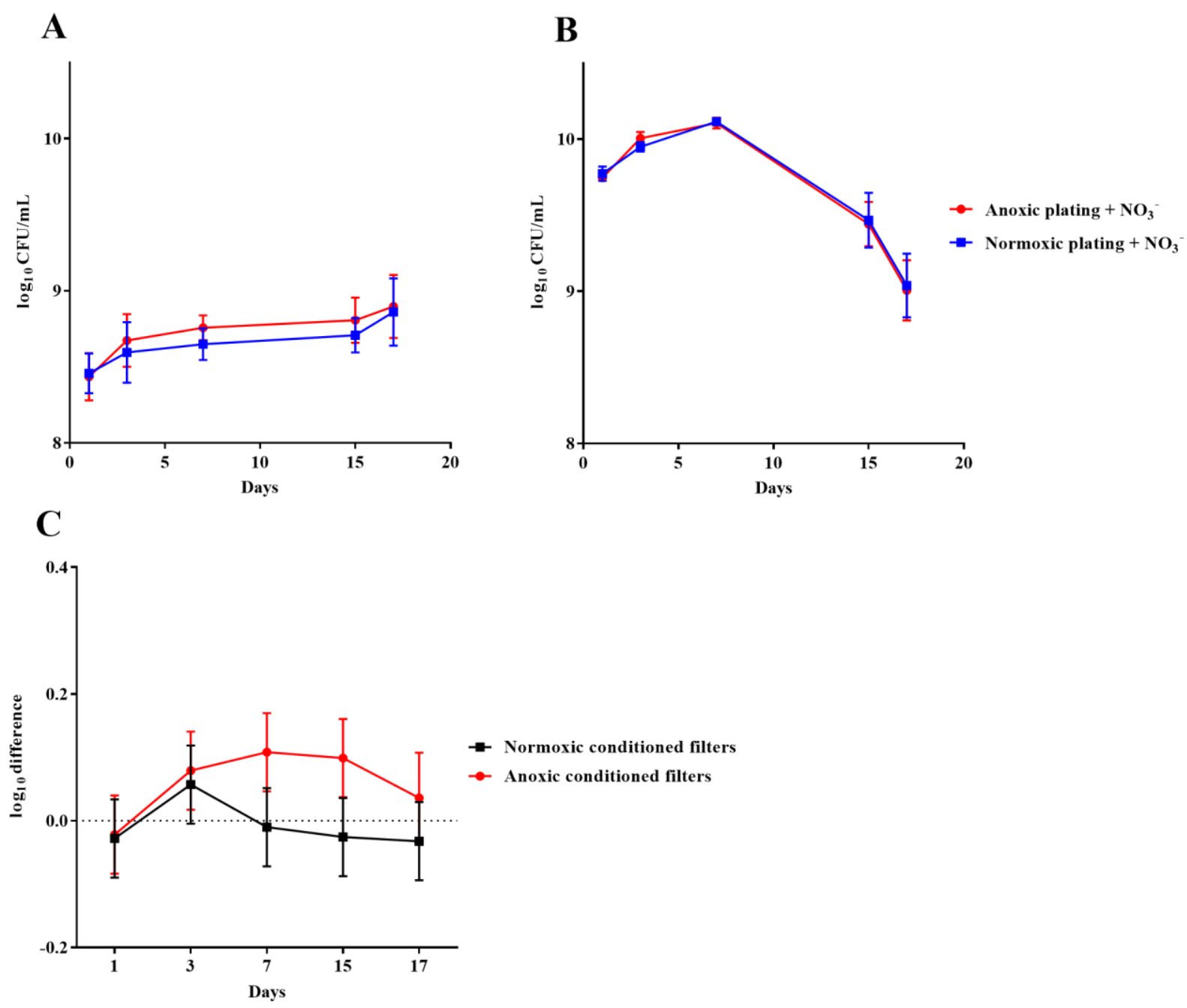

Fig. 3 - An oxygen intolerant subpopulation of Pseudomonas aeruginosa (PAO1) was generated in the filter biofilm model

590 Normoxic and anoxic colony forming units per milliliter (CFU/mL) of PAO1 over 17 days from 591 anoxically (A) and normoxically (B) conditioned filters. Symbols with error bars indicate the mean $592 \pm \mathrm{SEM}(\mathrm{n}=4) .+\mathrm{NO}_{3}{ }^{-}$refers to the addition of $10 \mathrm{mM} \mathrm{KNO}_{3}$ to $\mathrm{LB}$ agar plates. The log difference 593 (C) represents the difference in mean $\log \mathrm{CFU} / \mathrm{mL}$ between plating methods from the normoxically 594 and anoxically conditioned filters, respectively. The log difference was significantly higher $(\mathrm{p}=$ 5950.01 , linear regression) in the anoxically conditioned filters than the normoxically conditioned. Symbols with error bars indicate the mean + confidence intervals. 


\section{Oxygen restriction generates DTC pathogens}
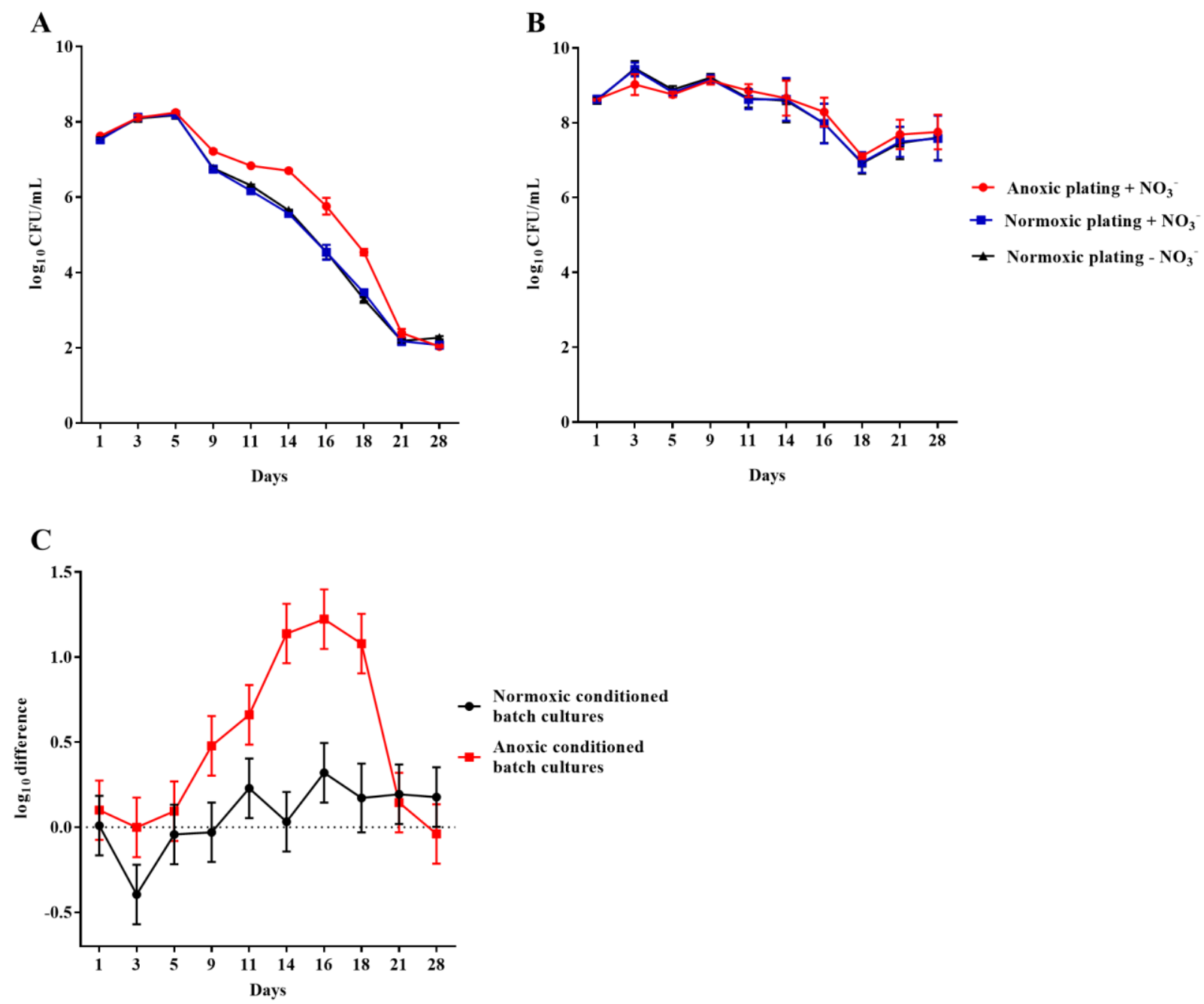

598 Fig. 4 - An oxygen intolerant subpopulation of Pseudomonas aeruginosa (PAO1) was

599 generated in the planktonic batch cultures

600 Normoxic and anoxic colony forming units per milliliter (CFU/mL) of PAO1 over 28 days from 601 anoxically (A) and normoxically (B) conditioned batch cultures. Symbols with error bars indicate 602 the mean $\pm \operatorname{SEM}(\mathrm{n}=4) . \pm \mathrm{NO}_{3}{ }^{-}$refers to the addition of $10 \mathrm{mM} \mathrm{KNO}_{3}$ to $\mathrm{LB}$ agar plates. The log 603 difference $(\mathrm{C})$ represents the difference in mean $\log \mathrm{CFU} / \mathrm{mL}$ between plating methods from the 604 normoxically and anoxically conditioned batch cultures, respectively. The log difference was 605 significantly higher ( $\mathrm{p}<0.0001$, linear regression) in the anoxically conditioned batch cultures than 606 the normoxically conditioned. Symbols with error bars indicate the mean + confidence intervals. 


\section{Oxygen restriction generates DTC pathogens}

$\mathbf{A}$

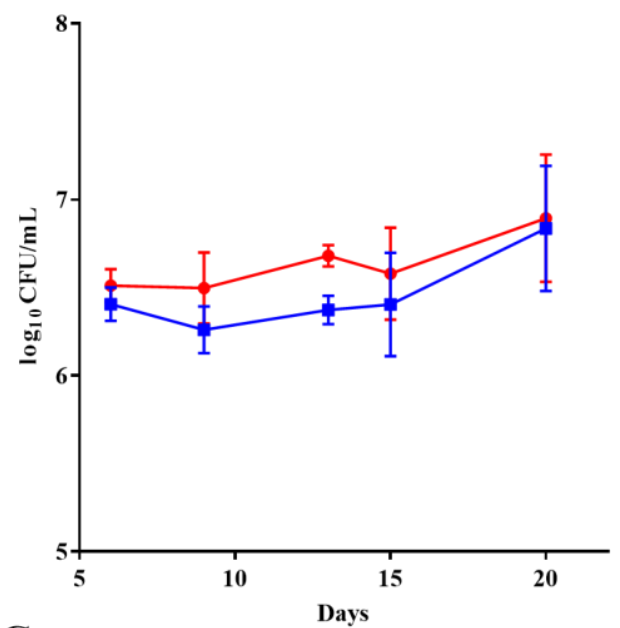

C

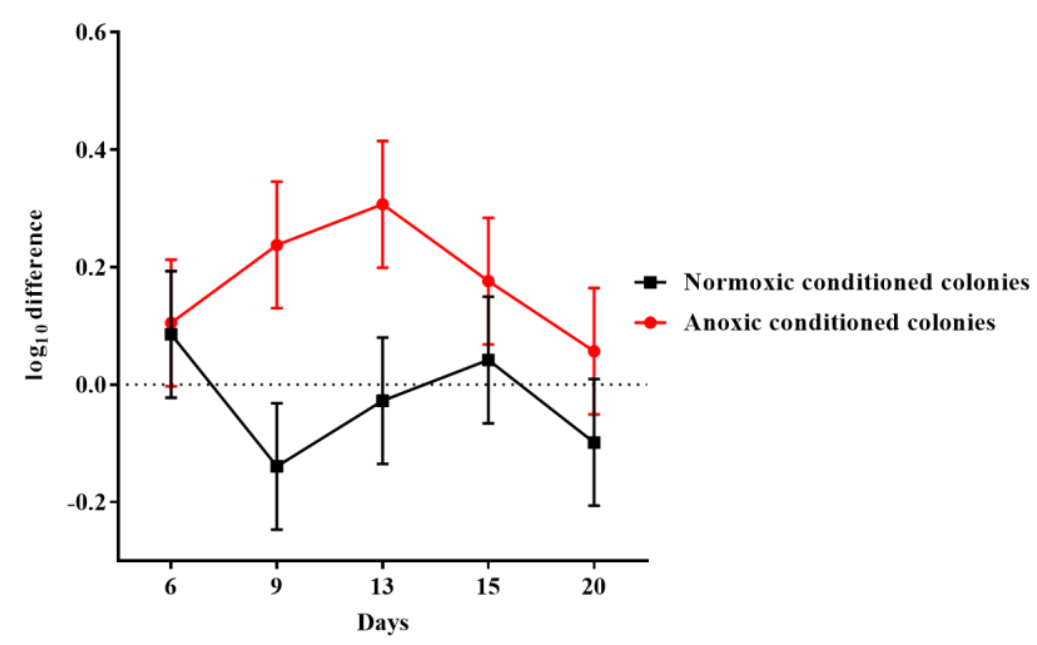

B

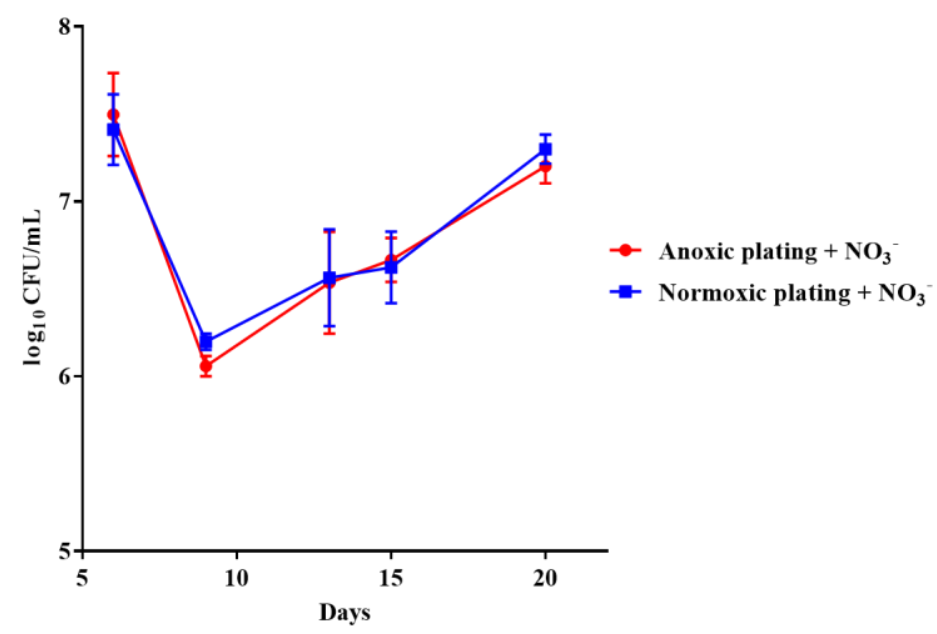

607
Fig. 5 - An oxygen intolerant subpopulation of Pseudomonas aeruginosa (PAO1) was generated in colonies

Normoxic and anoxic colony forming units per milliliter (CFU/mL) of PAO1 over 20 days from anoxically (A) and normoxically (B) conditioned colonies. Symbols with error bars indicate the mean $\pm \mathrm{SEM}(\mathrm{n}=3) .+\mathrm{NO}_{3}{ }^{-}$refers to the addition of $10 \mathrm{mM} \mathrm{KNO}_{3}$ to $\mathrm{LB}$ agar plates. The $\log$ difference $(\mathrm{C})$ represents the difference in mean $\log \mathrm{CFU} / \mathrm{mL}$ between plating methods from the normoxically and anoxically conditioned colonies, respectively. The log difference was significantly higher $(\mathrm{p}<0.0001$, linear regression) in the anoxically conditioned colonies than the normoxically conditioned. Symbols with error bars indicate the mean + confidence intervals. 


\section{Oxygen restriction generates DTC pathogens}

A

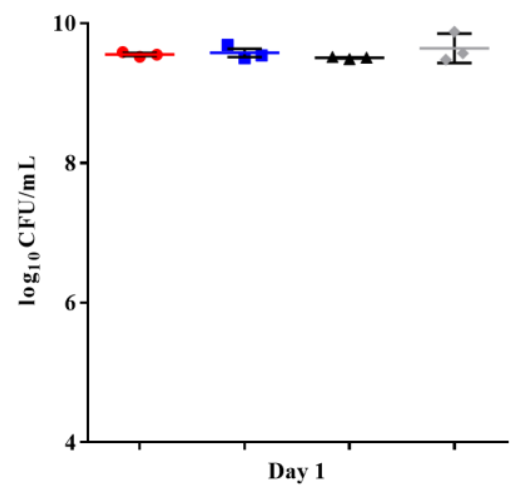

C

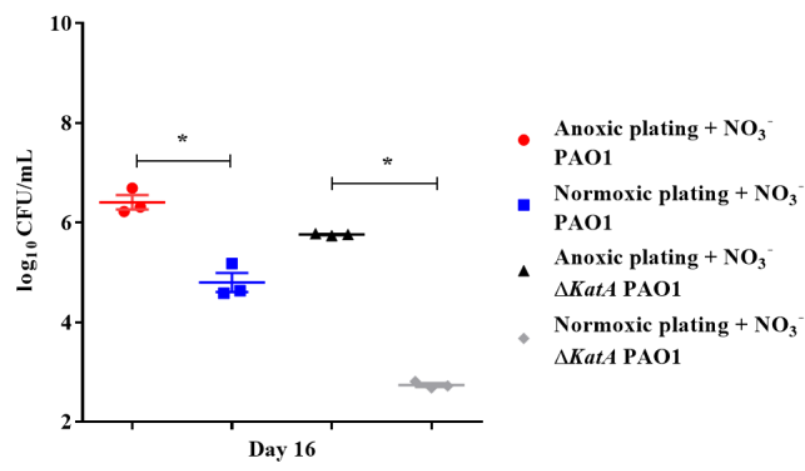

B

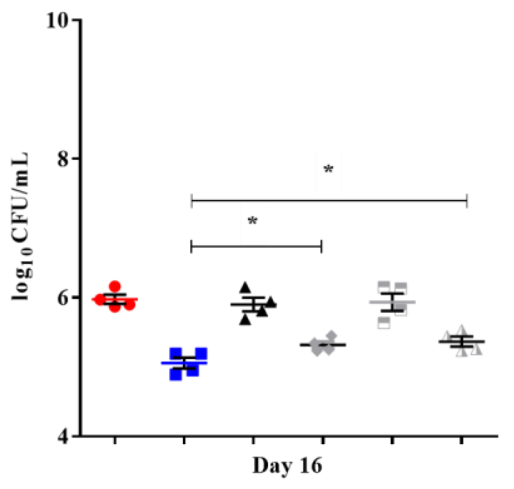

- Anoxic plating $+\mathrm{NO}_{3}$

- Normoxic plating $+\mathrm{NO}_{3}{ }^{-}$

$\Delta$ Anoxic plating $+\mathrm{NO}_{3}{ }^{-}+$sodium pyruvate

- Normoxic plating $+\mathrm{NO}_{3}+$ sodium pyruvate

$=$ Anoxic plating $+\mathrm{NO}_{3}+$ catalase

Normoxic plating $+\mathrm{NO}_{3}{ }^{-}+$catalase
619

620

621

622

623

624

625

626

627

628

629

630

631

632

633

634

Fig. 6 - Reactive oxygen species generates a DTC subpopulation of Pseudomonas aeruginosa (PAO1)

Normoxic and anoxic colony forming units per milliliter (CFU/mL) were determined for 24-hourold batch cultures (A) and 16-day-old anoxically conditioned batch cultures (B) of PAO1.

Normoxic CFU/mL was determined $\pm 0.3 \%$ sodium pyruvate (A and B), while addition of catalase was only tested for 16-day-old batch cultures. Symbols with error bars indicate the mean \pm SEM (n $=4) .+\mathrm{NO}_{3}{ }^{-}$refers to the addition of $10 \mathrm{mM} \mathrm{KNO}_{3}$ to $\mathrm{LB}$ agar plates. There was a significant difference between normoxic plating $\pm 0.3 \%$ sodium pyruvate $(\mathrm{p}=0.04$, one-way ANOVA test $)$ and normoxic plating \pm catalase $(\mathrm{p}=0.03$, one-way ANOVA test). Normoxic and anoxic determination of CFU/mL were determined for 16-day-old anoxically conditioned batch cultures of PAO1 and $\triangle k a t A$ PAO1 (C). Symbols with error bars indicate the mean \pm SEM $(n=3)$. Significant difference between anoxic and normoxic plating with both PAO1 and $\Delta k a t A$ PAO1 ( $\mathrm{p}=0.0014$ and $\mathrm{p}<0.0001$, respectively, one-way ANOVA test). 


\section{Oxygen restriction generates DTC pathogens}

A

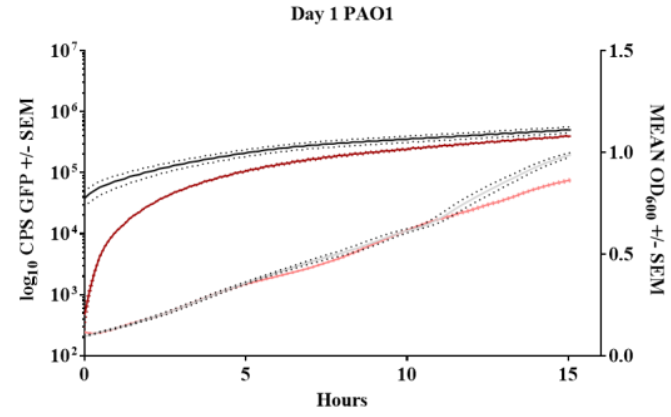

B

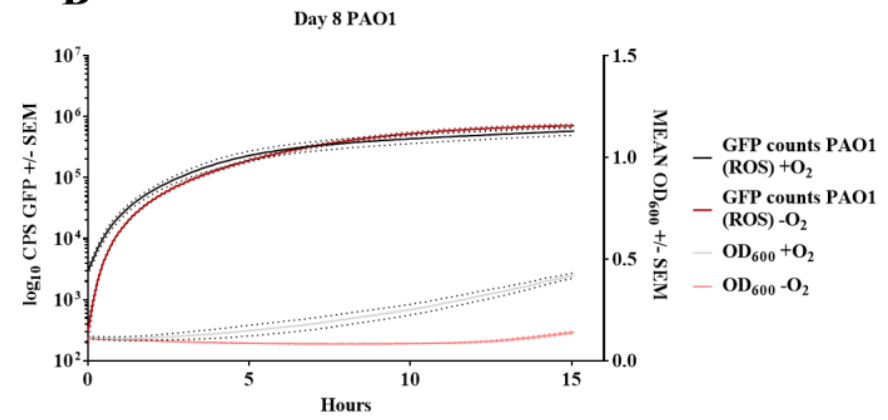

C

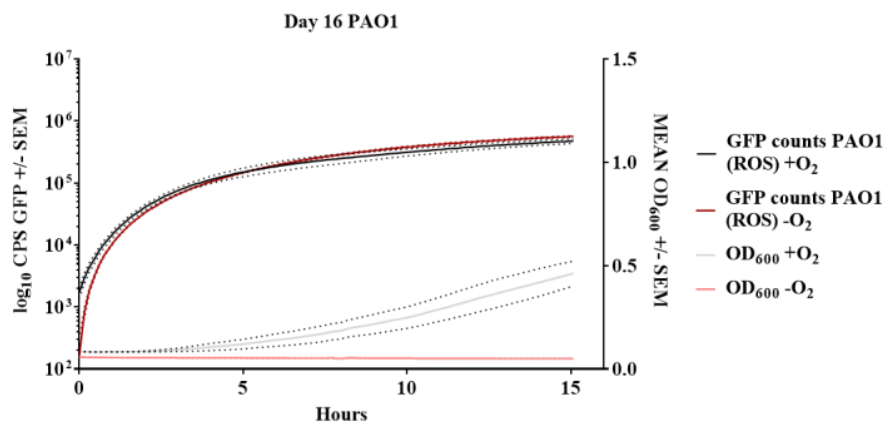

635

636

637

638

639

640

641

642

643

644

645

Fig. 7 - Increase in reactive oxygen species affects growth of anoxically conditioned

\section{Pseudomonas aeruginosa (PAO1) over time}

Determination of reactive oxygen species (ROS) and optical density (OD) at day 1 (A), 8 (B) and 16 (C) for anoxically $\left(-\mathrm{O}_{2}\right)$ and normoxically $\left(+\mathrm{O}_{2}\right)$ conditioned PAO1. ROS was measured as counts per second (CPS) when 2',7'dichlorodihydrofluorescein diacetate was converted to 2'7'dichlorofluorescein. Growth was measured with optical density (OD600) simultaneously to ROS measurement. Data is generated from 99 continuously measurements presented as a solid line with dots representing $\pm \operatorname{SEM}(n=4)$. 


\section{Oxygen restriction generates DTC pathogens}
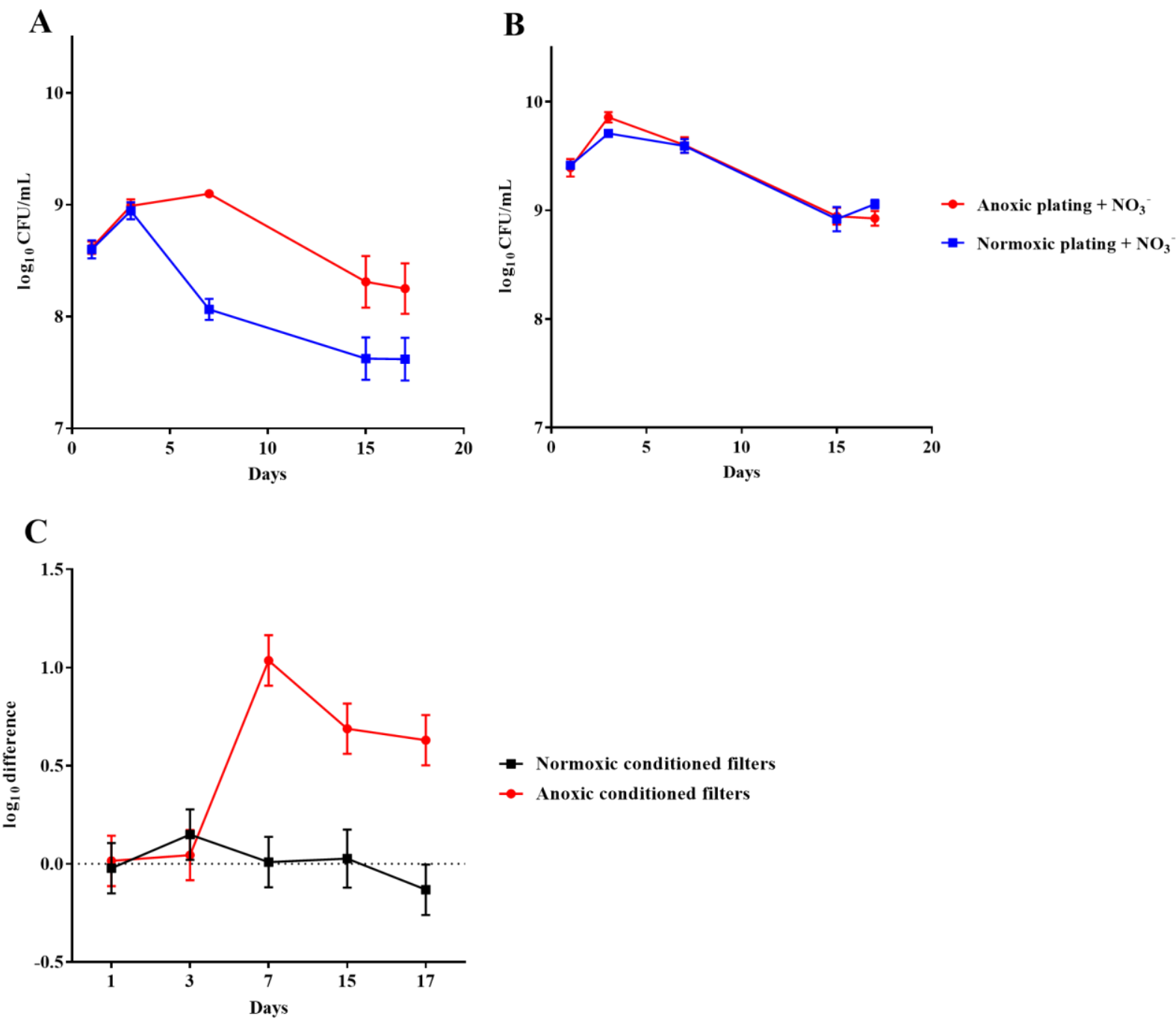

647 Fig. 8 - An oxygen intolerant subpopulation of Staphylococcus aureus (methicillin susceptible) was generated in the filter biofilm model

649 Normoxic and anoxic colony forming units per milliliter (CFU/mL) of Staphylococcus aureus over 65017 days from anoxically (A) and normoxically (B) conditioned filters. Symbols with error bars 651 indicate the mean $\pm \mathrm{SEM}(\mathrm{n}=4) .+\mathrm{NO}_{3}{ }^{-}$refers to the addition of $10 \mathrm{mM} \mathrm{KNO}_{3}$ to $\mathrm{LB}$ agar plates. 652 The $\log$ difference $(\mathrm{C})$ represents the difference in mean $\log \mathrm{CFU} / \mathrm{mL}$ between plating methods 653 from the normoxically and anoxically conditioned filters, respectively. The log difference was 654 significantly higher $(\mathrm{p}<0.001$, linear regression) in the anoxically conditioned filters than the 655 normoxically conditioned. Symbols with error bars indicate the mean + confidence intervals. 656 